\title{
Study of a tooth gel formulation for hygiene and oral sequelae management in irradiated patients
}

\author{
Ana Carolina Lara Ribeiro ${ }^{1}$, Marina Goulart da Silva ${ }^{1}$, Harley da Silva Tavares ${ }^{1}$, Ana Gabriela Reis Solano ${ }^{2}$, Ana Julia Pereira \\ Santinho Gomes ${ }^{1 *}$ \\ ${ }^{1}$ Laboratory of Pharmaceutical Development, Federal University of Sao Joao del Rei, Divinopolis, Brazil. \\ ${ }^{2}$ Laboratory of Microbiological Control of Pharmaceuticals, Federal University of Sao Joao del Rei, Divinopolis, Brazil.
}

\begin{tabular}{l}
\hline ARTICLE INFO \\
\hline Received on: 20/12/2019 \\
Accepted on: $23 / 03 / 2020$ \\
Available online: $05 / 06 / 2020$
\end{tabular}

\section{Key words:}

Formulation development, dentifrice, physicochemical properties, cancer patient.

\begin{abstract}
Cervical-facial radiotherapy causes innumerable sequelae, being systemic or restricted to the oral environment. The oral mucosa of these patients is profoundly compromised by radiotherapeutic treatment with or without chemotherapy, presenting several complications. Dentifrices containing sodium lauryl sulfate cause damage, as they lead to dryness of the mucosa. The objective of this work was to develop a dentifrice capable of minimizing xerostomia related to a lower abrasive effect, which was intended for hygiene, prevention of caries, control of dental biofilm, and tooth sensitivity in cancer patients. The qualitative composition and physicochemical characteristics of ten dentifrices were analyzed, which enabled the preparation of the proposed formulation (PF) that was analyzed periodically for 180 days. The quantitative analysis of spreadability not only indicated favorable behavior of the PF in relation to the packaging and storage conditions but also revealed the need to raise the propylene glycol concentration in the PF to avoid the occurrence of syneresis after 60 days. Furthermore, $\mathrm{pH}$ data showed that the $\mathrm{PF}$ is compatible with the $\mathrm{pH}$ of oral homeostasis thus avoiding the occurrence of dental demineralization. It is suggested that the PF has a singular composition and physicochemical quality to be used as a suitable dentifrice for patients undergoing anticancer therapy.
\end{abstract}

\section{INTRODUCTION}

Among the most frequent cancers, there are head and neck neoplasms, which include oral and nasal cavities, face, pharynx, larynx, and salivary glands. The most important treatment for these tumors is radiation therapy. However, its therapeutic compliance can bring innumerable sequelae to the patient, being systemic or restricted to the oral cavity (Jawad et al., 2015; Strojan et al., 2017).

According to Strojan et al. (2017) irradiated tissues have reduced blood circulation, which also affects tissue oxygenation. On reaching the salivary glands, there is an expressive reduction in the amount and quality of the saliva, which loses its antimicrobial, buffering, and dental remineralization potential.

\footnotetext{
"Corresponding Author

Ana Julia Pereira Santinho Gomes, Laboratory of Pharmaceutical Development, Federal University of Sao Joao del Rei, Divinopolis, Brazil. E-mail:ajpsant@ufsj.edu.br
}

The progressive salivary reduction, besides promoting the proliferation of microorganisms in the oral environment, induces a variety of complications, which initially are noninfectious, such as hemorrhage, mucositis, dry mouth, hypogeusia, osteoradionecrosis, lockjaw, dermatitis, and later dental caries, oral candidiasis, and infections (Neville et al., 2016; Sciubba and Goldenberg, 2006).

Basic oral care is considered as a basis of supportive care in oncology, mainly for irradiated patients (Hong et al., 2019). It is known that the oral hygiene of patients worsens significantly both during and after the period of radiotherapy treatment, and an accumulation of dental biofilm predisposing patients to oral diseases is observed. The central cause of this could be related to the fact that patients were unable to use the same hygiene products used before being submitted to therapy (such as dentifrices) due to oral mucosal involvement after radiotherapy sessions (Vissink et al., 2010). These data corroborate with those of Mercadante et al. (2017).

Considering the dentifrice composition, a widely used cleansing agent is sodium lauryl sulfate (SLS), an anionic 
surfactant that can cause an irritation in sensitized mucous, palate alteration, ulceration, or epithelia flaking, thereby promoting a burning sensation and favoring halitosis (Sälzer et al., 2016). The limitation of its use is evident in dental products for patients undergoing head and neck radiotherapy (H \& NRT) (Andrews and Griffiths, 2001).

Basic oral care has an important role, considering that H\&NRT patients become significantly immunosuppressed as a result of cancer therapies. Nowadays, there are several types of dentifrices available, which have a great diversity in terms of their qualitative and quantitative composition. However, none of these formulations meet the needs of such patients. Inevitably, after a few weeks of treatment, their oral mucosa will be sensitive and inflamed leading to discomfort from the use of adult dentifrices. Infant dentifrices provoke a less discomfort due to their composition, which present a less abrasive profile, being chosen by the user for this category of patients (Cvikl et al., 2017; Stovell et al., 2013).

In this sense, the objective of this study was to develop a dentifrice containing a lower abrasive amount and to prevent caries, dental biofilm control, and tooth sensitivity for hygiene and oral sequelae management in irradiated patients. In addition, the physicochemical evaluation of the proposed formulation (PF) was performed.

\section{MATERIALS AND METHODS}

\section{Materials}

Xanthan gum and triclosan were purchased from All Chemistry (São Paulo, Brazil). Sodium fluoride and Poloxamer ${ }^{\circledR}$ 407 were purchased from Via Farma (São Paulo, Brazil). Potassium nitrate was purchased from Êxodo (Sumaré, Brazil). A colloidal silicon dioxide was obtained from Genix (Anápolis, Brazil). Sucralose was purchased from Fagron (Embu das Artes, Brazil). The raspberry flavor was donated by Georges Broemmé (Carmo da Mata, Brazil). Carboxymethylcellulose sodium as cellulose gum, propylene glycol, glycerol analytical grade, sodium saccharin, and microcrystalline cellulose were purchased from Synth (Diadema, Brazil). Methylparaben and propylparaben analytical grade and SLS were obtained from Vetec (Duque de Caxias, Brazil).

Nine infant dentifrice formulations were selected for the present work and also an extemporaneous compounding preparation, as follows: dental cream Scooby-Doo Dentil, Suavetex, tutti-frutti flavor (C1); dental cream Tralala Kids, Phisalia, tutti-frutti flavor (C2); dental cream Tralala Kids, Phisalia, bubble gum flavor (C3); dental gel Cocorico, Bitufo, tutti-frutti flavor (G4); dental gel, Bitufo, tutti-frutti flavor (G5); dental gel Malvatrikids for 4-7 year old, Daudt, tutti-frutti flavor (G6); dental gel anticaries Colgate Smiles, Colgate-Palmolive, bubble fruit flavor (G7); dental gel Tandy, Colgate-Palmolive, tutti-frutti flavor (G8); dental gel Adventure Time Sanifill, Cosmed, tutti-frutti flavor (G9); and also an official formulation available as tooth gel for oral hygiene prepared in accordance with the Brazilian Pharmacopeia National Form (G10). Table 1 shows the respective compositions.

The qualitative composition of these products was evaluated, and the $\mathrm{pH}$ and spreadability were determined to guide the physicochemical properties of the PF.

\section{Preparation of PF}

After the previous tests employing different concentrations of thickening agent $(2.0 \%, 4.0 \%$, and $8.0 \% \mathrm{w} / \mathrm{w})$, the concentration of $4.0 \% \mathrm{w} / \mathrm{w}$ of xantham gum was chosen. The other ingredients and respective concentrations were selected based on the minimal concentrations mentioned by Ciancio (2007) and Rowe et al. (2012).

The PF was designed to contain active fluoride according to the needs of adults undergoing cancer treatment, nonionic emulsifying, antiseptic and desensitizing agents, as well as abrasive, thickening, humectant, antimicrobial preservative, sweetening, and flavoring substances. Based on this approach, the composition studied contained sodium fluoride $(0.243 \% \mathrm{w} / \mathrm{w})$, equivalent to $1,500 \mathrm{ppm}$ of active fluoride ion, poloxamer 407

Table 1. Composition of dentifrices nominated for assessment.

\begin{tabular}{|c|c|}
\hline Code & Composition \\
\hline $\mathrm{C} 1$ & $\begin{array}{l}\text { Hydrated silica, glycerol, SLS, cellulose gum, CI 16255, sodium saccharin, calcium carbonate, methylparaben, propylparaben, } 1,000 \text { ppm of fluoride ion as sodium } \\
\text { monofluorophosphate (MFP), and water }\end{array}$ \\
\hline $\mathrm{C} 2$ & $\begin{array}{l}\text { Hydrated silica, glycerol, SLS, cellulose gum, CI 16255, sodium saccharin, calcium carbonate, methylparaben, propylparaben, sorbitol, PEG-8, xylitol, D-limonene, } \\
\text { alcohol, sodium silicate, benzyl alcohol, 1,100 ppm of fluoride ion as MFP, and water }\end{array}$ \\
\hline $\mathrm{C} 3$ & $\begin{array}{l}\text { Hydrated silica, glycerol, SLS, cellulose gum, CI 42090, sodium saccharin, calcium carbonate, methylparaben, propylparaben, sorbitol, PEG-8, xylitol, D-limonene, } \\
\text { alcohol, sodium silicate, benzyl alcohol, 1,179 ppm of fluoride ion as MFP, and water }\end{array}$ \\
\hline G4 & $\begin{array}{l}\text { Hydrated silica, glycerol, SLS, cellulose gum, sodium saccharin, methylparaben, propylparaben, sorbitol, PEG-8, xylitol, D-limonene, alcohol, sucralose, triclosan, } \\
\text { xanthan gum, EDTA, and water. Without fluoride ion. }\end{array}$ \\
\hline G5 & $\begin{array}{l}\text { Hydrated silica, glycerol, SLS, cellulose gum, CI 17200, CI 42051, sodium saccharin, sorbitol, PEG-8, xylitol, D-limonene, } 1,100 \text { ppm of fluoride ion as sodium fluoride } \\
\text { (NaF), and water }\end{array}$ \\
\hline G6 & $\begin{array}{l}\text { Hydrated silica, glycerol, sodium sarcosinate, cellulose gum, CI } 45430 \text {, sodium benzoate, xylitol, sucralose, Malva sylvestris extract, } 1,000 \text { ppm of fluoride ion as NaF, } \\
\text { and water }\end{array}$ \\
\hline G7 & $\begin{array}{l}\text { Hydrated silica, SLS, cellulose gum, CI 16035, CI 17200, mica (CI 77019), titanium dioxide (CI 77891), sodium saccharin, sorbitol, PEG-12, D-limonene, eugenol, } \\
\text { cinnamal, 1,100 ppm of fluoride ion as NaF, and water }\end{array}$ \\
\hline G8 & $\begin{array}{l}\text { Hydrated silica, SLS, cellulose gum, CI 16035, CI 42090, sodium saccharin, sorbitol, PEG-8, PEG-12, D-limonene, eugenol, cinnamal, } 1,100 \text { ppm of fluoride ion as NaF, and } \\
\text { water }\end{array}$ \\
\hline G9 & Hydrated silica, glycerol, SLS, cellulose gum, CI 17200, CI 42051, sodium saccharin, sorbitol, PEG- 8 , xylitol, D-limonene, 1,100 ppm of fluoride ion as NaF, and water \\
\hline G10 & Microcrystalline cellulose, glycerol, SLS, cellulose gum, sodium saccharin, methylparaben, propylparaben, propylene glycol, and water. Without fluoride ion. \\
\hline
\end{tabular}


$(0.30 \% \mathrm{w} / \mathrm{w})$, triclosan $(0.10 \% \mathrm{w} / \mathrm{w})$, potassium nitrate $(5.0 \%$ $\mathrm{w} / \mathrm{w})$, colloidal silicon dioxide $(0.50 \% \mathrm{w} / \mathrm{w})$, xanthan gum $(4.0 \%$ $\mathrm{w} / \mathrm{w})$, propylene glycol $(1.0 \% \mathrm{w} / \mathrm{w})$, methylparaben $(0.065 \%$ $\mathrm{w} / \mathrm{w})$, propylparaben $(0.035 \% \mathrm{w} / \mathrm{w})$, sucralose $(0.05 \% \mathrm{w} / \mathrm{w})$, raspberry flavor Georges Broemmé ${ }^{\circledR}(1.0 \% \mathrm{w} / \mathrm{w})$, and purified water $(87.707 \% \mathrm{w} / \mathrm{w})$.

Initially, a preservative solution (PS) composed of methylparaben, propylparaben, and propylene glycol (6:3:91) was prepared according to the Brazilian Pharmacopeia National Form (2012). It was then placed in a digital ultrasonic bath, Soniclean Model 2PS, for 40 minutes: triclosan, sucralose, PS, flavor, poloxamer 407, sodium fluoride, and purified water. After solubilization, potassium nitrate, colloidal silicon dioxide, and xanthan gum were added, which, after swelling, provided the desired consistency of the PF (Swarbrick and Boylan, 2002). The PF was packed in white high-density polyethylene tubes and stored at a room temperature $\left(15^{\circ} \mathrm{C}-30^{\circ} \mathrm{C}\right)$ and a relative humidity of $60 \% \pm 5 \%$ for 180 days. The samples were submitted monthly, in triplicate, for the determination of $\mathrm{pH}$ and spreadability.

\section{pH determination}

The $\mathrm{pH}$ values of the semisolid preparations diluted 1:10 in purified water were determined in triplicate by using an MS Tecnopon pH meter (Gonçalves et al., 2011).

\section{Determination of the spreadability}

The spreadability of the samples was determined as per Pardeshi and Tapar method (2016). The samples were placed in a circular glass template, measuring $20.0 \mathrm{~cm}$ in diameter and 4.0 $\mathrm{mm}$ in thickness with a central hole of $12.0 \mathrm{~mm}$ in diameter on a laminated graph paper. The sample was added, in triplicate, to the central hole of this template, which was removed after dentifrice leveling. Another circular glass plate with a diameter of $20.0 \mathrm{~cm}$ and a weight of $225.80 \mathrm{~g}$ was placed on the sample; after 1 minute passed, the diameter increase covered by the dentifrice was determined. The following equation was applied:

$$
\mathrm{S}=\mathrm{d} 2 . \pi / 4
$$

where $\mathrm{S}=$ spreadability of the sample for $i$ weight $\left(\mathrm{mm}^{2}\right)$, $d=$ medium diameter $(\mathrm{mm})$, and $\pi=3.14$.

\section{Statistical analyses}

The analyses were performed using GraphPad Prism ${ }^{\circledR}$ version 5.0 (GraphPad Software Inc., CA). The results obtained in triplicate were presented as the arithmetic mean of the values and standard deviation ( \pm SD). The one-way analysis of variance and Tukey's HSD post-test for multiple comparisons as appropriate were performed; the $p$-value was set at $<0.05$ as significant.

\section{RESULTS AND DISCUSSION}

Although the dentifrice is a product of external use, the oral mucosa of individuals with cervical-facial cancer is profoundly compromised by radiotherapy treatment with or without chemotherapy. This means that, in this case, this type of product must be constituted by appropriate substances for the public in question, without losing its desired properties.

The qualitative composition of a compounded dental gel formulation (Brazilian Pharmacopeia National Form, 2012) and nine dentifrices for infants was evaluated since this product line presents a lower abrasive effect and a sweet flavor compared with other dentifrices indicated for adults. Therefore, it is understood, that individuals with complications in the oral mucosa choose this line of products, aiming at less discomfort during the process of oral hygiene.

According to Pader (1992), the dentifrices are composed of abrasive, surfactant, humectant, thickener, flavoring, and water. They may also contain remineralizing, desensitizing, and antimicrobial agents, among others.

Among the selected products, several components were observed; however, some of them might increase the patient's discomfort during use, as well as provoking adverse reactions.

One of these substances is ethyl alcohol, present in 30\% of the analyzed products (3/10). This substance is a potent cause of oral mucosa peeling that can cause adverse reactions such as mouth ulcers, burning sensation, gingivitis, dry mouth (Tuncer Budanur et al., 2016), and hyposalivation, leading to a higher exposure to locally acting carcinogens. Moreover, its local effect may increase the permeability of the mucosa by dissolving the lipid component of the epithelium and provide indirect cellular damage through acetaldehyde; it also may enhance the toxicity of other agents (Russo et al., 2018).

Multifunctional excipients such as glycerin and sorbitol exhibit the humectant and sweetening properties (Stovell et al., 2013). However, they are polyalcohols with three and six alcoholic hydroxyls (R3-C-OH), respectively, which, in turn, interact with water through hydrogen bonds and may favor tissue dryness (Sinko and Singh, 2011). They are commonly found in dentifrices, being present in $80 \%(8 / 10)$ and $70 \%(7 / 10)$ of the samples analyzed.

Propylene glycol, which has two alcoholic hydroxyls (R3-C-OH), was found in only $10 \%(1 / 10)$ of the products. It is noteworthy that this humectant was selected to compose the PF to protect the gel against syneresis (Florence and Attwood, 2016; Swarbrick and Boylan, 2002), besides acting as the solvent for the parabens, and to potentiate antimicrobial activity when used in the concentration of $2.0 \%-5.0 \%$ (Rowe et al., 2012).

Sodium saccharin, a synthetic sweetener, observed in $90 \%$ of the analyzed compositions $(9 / 10)$, may promote adverse reactions, such as skin rash, nausea, and vomiting, since it is an analog of sulfonamide (Florence and Attwood, 2016; Wulf and Matuszewski, 2013). Recently, it was found that the consumption of this sweetener may be meaningfully linked to the risk of Alzheimer's disease (Lohner et al., 2017); furthermore, other studies exhibited specific changes in the gut microbiota related to modifications in the metabolic pathways associated with glucose tolerance and dysbiosis in human subjects, mainly with the ingestion of saccharin (Ruiz-Ojeda et al., 2019).

In addition, $80 \%$ of the dentifrices analyzed (8/10) present a dye in the composition, with the purpose of making the product more attractive, and among them, the following were observed: CI 16255 (Ponceau $\times$ Red 4R) in products C1 and C2; CI 42090 (bright blue) in products C3 and G8; CI 17200 (Red 33) in products G5, G7, and G9; CI 42051 (blue patent) in products G5 and G9; CI 45430 (erythrosine red) in product G6; CI 16035 (Allura Red) in products G7 and G8; and CI 77891 (white) and CI 77019 (white) both in product G7. 
The recent reviews describe that different chemical classes of dyes (azo being amaranth, Allura Red, carmoisine, Ponceau 4R, sunset yellow, and tartrazine; indoid being indigo carmine; quinophtalone being quinolone yellow; triarylmethane being brilliant blue and patent blue $\mathrm{V}$; and xanthene being erythrosine) present the toxicological and mutagenic potential, among other serious adverse reactions (Pérez-Ibarbia et al., 2016; Rowe et al., 2012). In this sense, it was decided not to add this type of adjuvant to the PF.

Moreover, being a product for infants, $80 \%$ of the dentifrices selected for analysis $(8 / 10)$ have a low fluoride content as the active remineralizing ingredient $(1,000-1,179 \mathrm{ppm}$ of fluoride ion), $20 \%$ of which are not fluoridated (2/10).

It is emphasized that fluoride plays an important role in the combat and the reduction of dental caries because it decreases the solubility of dental enamel by giving a greater resistance toward the presence of the acids generated by cariogenic bacteria, especially Streptococcus mutans and Lactobacillus casei. In addition, this active ingredient can reduce enamel breaking and accelerate the natural process of remineralization (Oliveira and Lorscheider, 2008).

Given this context, the PF was drawn up with substances that are capable of providing cleaning, a pleasant odor and palate, antiplaque protection, desensitizing effect, and adequate fluorine content (1,500 ppm of fluoride ion), using minimum usual concentrations, according to Rowe et al. to make the product appropriate for patients undergoing cancer treatment, in addition to minimizing possible adverse reactions (Rowe et al., 2012).

The developed PF is a gel-type dentifrice, without the presence of SLS that was present in $100 \%$ of the analyzed products (10/10). The purpose of excluding this adjuvant was to avoid a negative impact on the oral situation of the patient submitted to radiotherapy, thus not worsening their condition. Jackson et al. reported the occurrence of dryness and cracking of the skin due to the repeated and prolonged exposure to SLS that can lead to contact dermatitis and xerostomia development (Jackson et al., 2014).

In this direction, the cleaning agent was replaced by poloxamer 407, a nonionic emulsifying copolymer. Such a substance is used in a wide variety of pharmaceutical preparations, being considered as nontoxic and nonirritating, and also, the body does not metabolize it. In vivo studies have shown that poloxamer 407 is not a sensitizing agent when applied to the gums, eyes, and skin of rabbits and dogs (Rowe et al., 2012).

Triclosan has been used in the PF with the purpose of bacterial antiplaque, in addition to present anti-inflammatory properties that help to recover the damaged oral mucosa (Saunders et al., 2013). In general, it is used in combination with a copolymer, in this study, being poloxamer 407, which can increase the retention of triclosan in the oral cavity and, consequently, increase its action time (Davies, 2007; Teles and Teles, 2009).

The clinical studies and systematic reviews have demonstrated the ability of triclosan present in dentifrices to reduce bacterial plaque and improve gingivitis (Davies et al., 2004; Hioe and van der Weijden, 2005; Triratana et al., 2015). Moreover, the addition of sodium fluoride prevents the formation of bacterial biofilm and assists in dental remineralization by inhibiting the bacterial acidity that result from carbohydrate metabolism.
Therefore, it is relevant to add sodium fluoride together with inputs that promote antibacterial action.

Sucralose added to the PF as a synthetic sweetener does not interfere with glucose absorption, carbohydrate metabolism, and consequently, insulin secretion, which characterizes it as a safe sweetener for use by diabetic individuals. Another associated advantage is the fact that it is a noncariogenic substance that is capable of helping to maintain oral health (Rodero et al., 2009).

Finally, the PF contains potassium nitrate due to its effective desensitizing action, as described by Zado and Pilatti (2016). Thus, it is understood that the PF is composed of adjuvants that are specifically suitable for the disclosed target public.

Parallel to composition evaluation, it is known that the $\mathrm{pH}$ is a relevant parameter for the evaluation of oral hygiene products since these formulations should have a $\mathrm{pH}$ compatible with the homeostasis $\mathrm{pH}$ of the oral environment to avoid damages to dental hard tissues (Loke et al., 2016). In addition, spreadability is another important property of these products since it shows the extent of area, to which the formulation readily spreads on application to the target surface in addition to its use as quality and stability parameters (Pardeshi and Tapar, 2016).

Figure 1 shows two physicochemical parameters, $\mathrm{pH}$ and spreadability, of nine infant dentifrices and the compounded dentifrice gel formulation (Brazilian Pharmacopeia National Form, 2012) analyzed in this study compared with the PF.

The pathogenesis of dental erosion is directly related to the buffering capacity and the rate of salivary secretion (Abou Neel et al., 2016), which has been compromised after the initiation of cancer treatment. Therefore, oral hygiene products should have a $\mathrm{pH}$ compatible with the homeostasis $\mathrm{pH}$ of the oral environment, which means around 6.5 or higher, with undesirable values below 5.50 due to the phenomenon of dental demineralization (Mahmoud and Omar, 2018).

Figure 1A shows that the initial $\mathrm{pH}$ of the $\mathrm{PF}$, adjusted to 7.0 , did not show a significant difference $(p>0.05)$ in relation to the products $\mathrm{G} 7(\mathrm{pH}=7.0)$ and $\mathrm{G} 10(\mathrm{pH}=6.7)$. However, there are, in the market, infant dentifrices with $\mathrm{pH}$ below the initial value of the $\mathrm{PF}$, recorded as 6.8. In this case, two products are mentioned: $\mathrm{G} 4(\mathrm{pH}=5.0)$ and $\mathrm{G} 5(\mathrm{pH}=6.0)$. Six other products presented values above the initial $\mathrm{pH}$ of the $\mathrm{PF}(\mathrm{C} 1, \mathrm{C} 2, \mathrm{C} 3, \mathrm{G} 6$, G8, and G9), ranging from 7.3 (G6) to 9.65 (C3). All these eight products displayed significantly a different $\mathrm{pH}(p<0.001)$ in comparison with the PF when recently prepared.

The erosive potential of oral pediatric liquid medications was described by Mahmoud and Omar (2018) through measuring the inherent $\mathrm{pH}$. The results found in $\mathrm{pH}$ values ranging between 3.5 and 6.9 indicated that this physicochemical parameter presents a damaging effect on tooth structure. Based on this, it could be observed that the PF in the present work was formulated from a suitable $\mathrm{pH}$, being similar to six other infant dentifrices studied (C1, C2, C3, G6, G8, and G9).

It is noticed that the creams $(\mathrm{C} 1, \mathrm{C} 2$, and $\mathrm{C} 3)$ exhibited the $\mathrm{pH}$ values greater than 8.0 (Fig. 1A). This can be attributed to the presence of calcium carbonate as an alkaline abrasive agent in such formulations.

Moreover, spreadability is an attribute that plays a key role in the development of semisolid products because it has an 
important impact on the rheological characteristics (Savary et al., 2019).

Figure 1B shows the results of the spreadability test that is based on resistance to forced movement (Alves et al., 2005; De Paula et al., 1998). These results correspond to the relationship between the spreading area with the applied force on the product and the limiting effort, which corresponds to spreadability. The PF presented an initial spreadability $\left(\mathrm{mm}^{2}\right)$, which was significantly higher $(p<0.001)$ compared with $80 \%$ of the analyzed products (C1, C2, C3, G5, G6, G7, G8, and G9). However, 20\% of the dentifrices in questions (G4 and G10) exhibited a statistically larger spreadability than the others.

Figures 2 and 3 show, respectively, the evaluation of the $\mathrm{pH}$ and spreadability of the PF during the period of 180 days of the study.

The PF maintained the initial $\mathrm{pH}$ (7.0) without significant changes for 30 days (Fig. 2). However, there was a significant reduction from the 60 th day $(p<0.05)$, achieving $\mathrm{pH} 6.12$ by the end of the study period with extremely significant changes $(p<$ $0.001)$. On the other hand, even with a reduction of $0.50 \mathrm{pH}$ units after 60 days of storage, the PF still showed compatibility with the

A

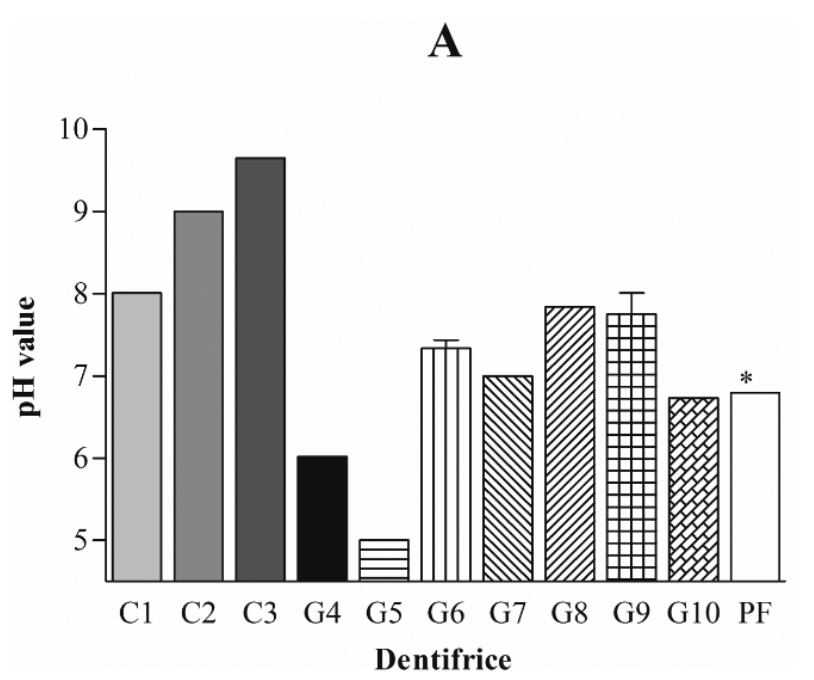

$\mathrm{pH}$ of oral homeostasis (approximately 6.50) and above the critical $\mathrm{pH}$ (5.50), avoiding the occurrence of dental demineralization.

The PF maintained an initial spreadability of $962.1 \mathrm{~mm}^{2}$ for 60 days' storage at room temperature (Fig. 3). However, a significant reduction was observed from the 90th day $(p<0.01)$, which achieved $856.5 \pm 88.4 \mathrm{~mm}^{2}$, remaining until the end of the study period without significant changes $(p>0.05)$. This result suggests that the concentration of propylene glycol used in the PF was not able to effectively prevent the phenomenon of syneresis observed after 90 days of the study. To avoid the occurrence of this phenomenon, the concentration of propylene glycol in the PF should be increased.

Florence and Attwood verified a decrease in the syneresis of an acidic gel from Plantago albicans seed gum, by the addition of electrolyte, glucose, and sucrose and also by increasing the gum concentration. They observed that, with low $\mathrm{pH}$, intense synergism occurred, probably due to the loss of water of hydration and the formation of intramolecular hydrogen bonds, reducing the attraction of the solvent by the macromolecules (Florence and Attwood, 2016). Analogously, this explains the results of the present work. Thus, it is suggested that the $\mathrm{pH}$ reduction of the $\mathrm{PF}$ detected after the 60th day (Fig. 2) may be related to the reduction

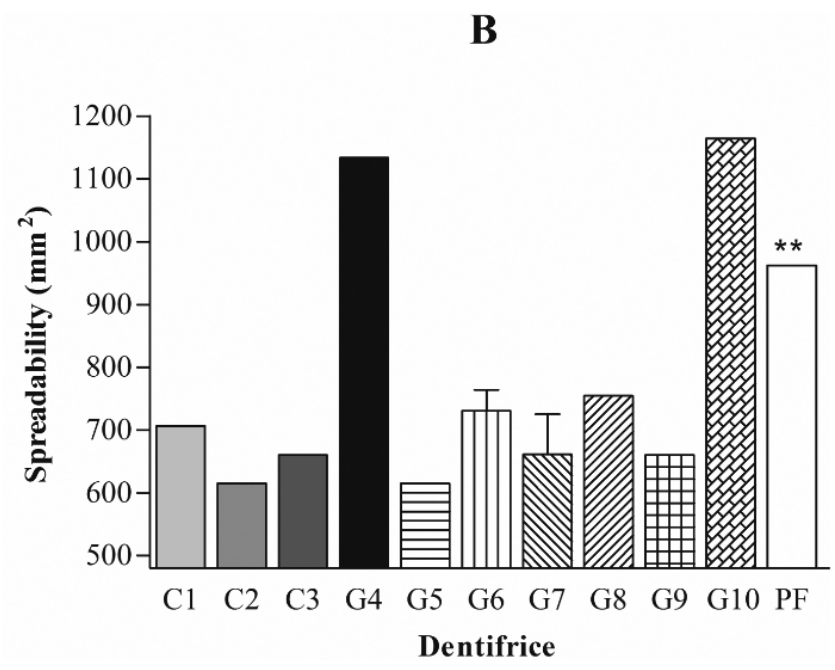

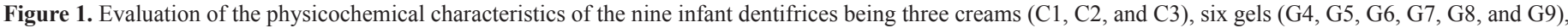
and the extemporaneous compounding tooth gel (G10) analyzed in this study in comparison with a PF in its first day $(n=3)$. A: pH. B: Spreadability.

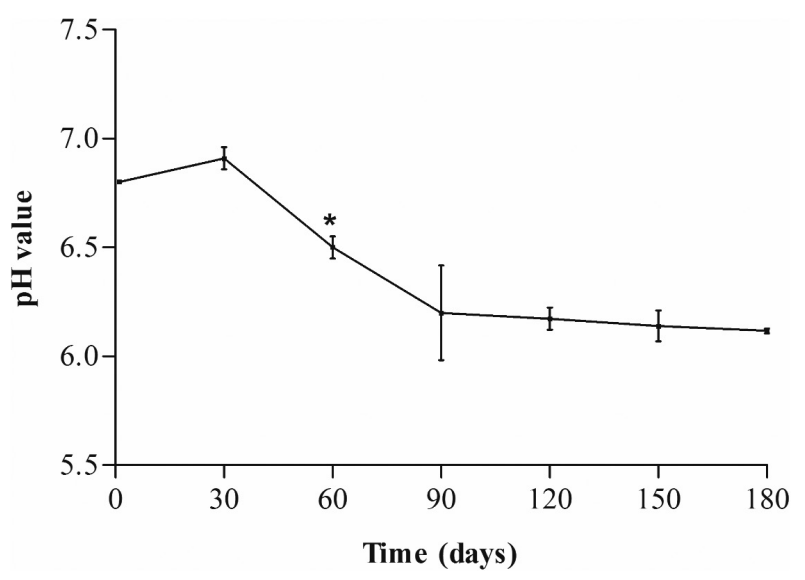

Figure 2. Evaluation of the $\mathrm{pH}$ of $\mathrm{PF}$ during 180 days.

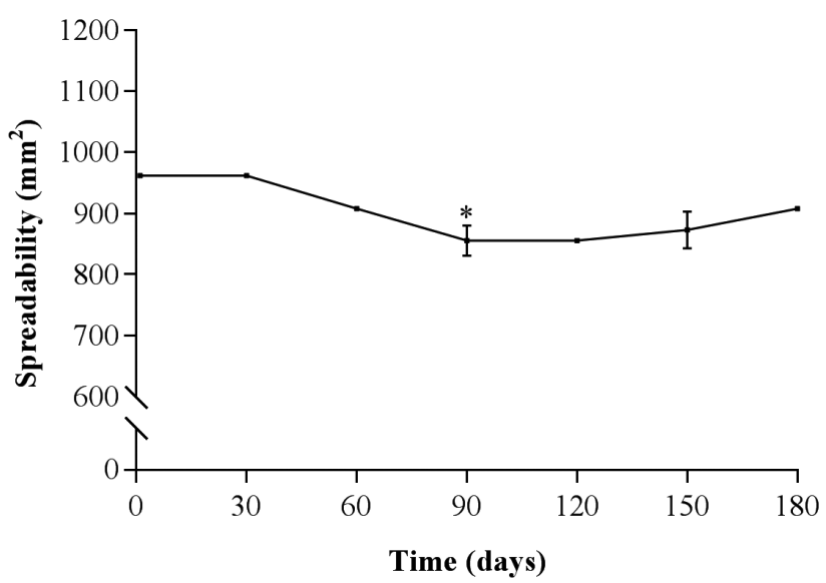

Figure 3. Evaluation of the spreadability of PF during 180 days. 
of spreadability (Fig. 3). On the contrary, even with an approximate reduction of $105 \mathrm{~mm}^{2}$ (Fig. 3), the PF was still superior to the spreadability of six dentifrices selected for this study, being $\mathrm{C} 1$, $\mathrm{C} 2$, C3, G4, G5, G6, G8, and G9, ranging from $615.44 \mathrm{~mm}^{2}(\mathrm{C} 2$ and $\mathrm{G} 5)$ to $754.4 \mathrm{~mm}^{2}(\mathrm{G} 8)$, as shown in Figure 1B.

\section{CONCLUSION}

A dentifrice formulation containing specific ingredients that are more convenient for oral hygiene and sequelae management in irradiated patients has been developed. It was observed that the PF showed a superior spreadability compared with the analyzed products. The need to increase the propylene glycol concentration in the PF to avoid the occurrence of syneresis after 60 days was also noted. Although $\mathrm{pH}$ decreased after this period, it remained until the end of the study period without significant changes and remained above the critical value for the occurrence of dental demineralization (5.50). It is suggested that the PF has a unique composition and physicochemical quality to be used as a suitable dentifrice for patients undergoing anticancer therapy.

\section{CONFLICT OF INTEREST}

The authors report that they do not have any conflicts of interest.

\section{FUNDING}

\section{None.}

\section{REFERENCES}

Abou Neel EA, Aljabo A, Strange A, Ibrahim S, Coathup M, Young AM, Bozec L, Mudera V. Demineralization-remineralization dynamics in teeth and bone. Int J Nanomed, 2016; 11:4743-63.

Alves PM, Pohlmann AR, Guterres SS. Semisolid topical formulations containing nimesulide-loaded nanocapsules, nanospheres or nanoemulsion: development and rheological characterization. Pharmazie, $2005 ; 60: 900-4$.

Andrews N, Griffiths C. Dental complications of head and neck radiotherapy: Part 1. Aust Dent J, 2001; 46:88-94.

Brazilian pharmacopeia National Form [ONLINE]. Available via: file:///C:/Users/Usuario/Downloads/Formulario\%20NACIONAL\%20 FARMACOPEIA\%20INGLES\%20com\%20alerta.pdf (Accessed 19 September 2017).

Ciancio SG. Dental products. In: Swarbrick J. (ed.). Encyclopedia of pharmaceutical technology. Informa Health Care, New York, NY, pp 891-907, 2007.

Cvikl B, Lussi A, Moritz A, Gruber R. Dentifrices for children differentially affect cell viability in vitro. Clin Oral Investig, 2017; 21(1):453-61.

Davies RM, Ellwood RP, Davies GM. The effectiveness of a toothpaste containing triclosan and polyvinyl-methyl ether maleic acid copolymer in improving plaque control and gingival health: a systematic review. J Clin Periodontol, 2004; 31:1029-33.

Davies RM. The clinical efficacy of triclosan/copolymer and other common therapeutic approaches to periodontal health. Clin Microbiol Infect, 2007; 13(Suppl 4):25-9.

De Paula IC, Ortega GG, Bassani VL, Petrovick PR. Development of ointment formulations prepared with Achyrocline satureioides spraydried extracts. Drug Dev Ind Pharm, 1998; 24:235-41.

Florence AT, Attwood D. Physicochemical principles of pharmacy: in manufacture, formulation and clinical use. Pharmaceutical Press, London, UK, 2016.

Gonçalves GMS, Srebernich SM, Souza JAM. Stability and sensory assessment of emulsions containing propolis extract and/or tocopheryl acetate. Braz J Pharm Sci, 2011; 47:585-92.

Hioe KP, van der Weijden GA. The effectiveness of selfperformed mechanical plaque control with triclosan containing dentifrices. Int J Dent Hyg, 2005; 3:192-204.

Hong CHL, Gueiros LA, Fulton JS, Cheng KKF, Kandwal A, Galiti D, Fall-Dickson JM, Johansen J, Ameringer S, Kataoka T, Weikel D, Eilers J, Ranna V, Vaddi A, Lalla RV, Bossi P, Elad S. Systematic review of basic oral care for the management of oral mucositis in cancer patients and clinical practice guidelines. Support Care Cancer, 2019;27(10):3949-67.

Jackson CT, Paye M, Maibach HI. Mechanism of skin irritation by surfactants and anti-irritants* for surfactant-based products. In: Barel AO, Paye M, Maibach HI (eds.). Handbook of cosmetic science and technology. CRC Press, Boca Raton, Florida, pp 353-65, 2014.

Jawad H, Hodson NA, Nixon PJ. A review of dental treatment of head and neck cancer patients, before, during and after radiotherapy: part 1. Brit Dent J, 2015; 218:65-8.

Lohner S, Toews I, Meerpohl JJ. Health outcomes of nonnutritive sweeteners: analysis of the research landscape. Nutr J, 2017; 16:55.

Loke C, Lee J, Sander S, Mei L, Farella M. Factors affecting intra-oral $\mathrm{pH}$ - a review. J Oral Rehabil, 2016; 43:778-85.

Mahmoud EF, Omar OM. Erosive and cariogenic potential of various pediatric liquid medicaments on primary tooth enamel: a SEM study. Dent Med Probl, 2018; 55:247-54.

Mercadante V, Al Hamad A, Lodi G, Porter S, Fedele S. Interventions for the management of radiotherapy-induced xerostomia and hyposalivation: a systematic review and meta-analysis. Oral Oncology, $2017 ; 66: 64-74$.

Neville BW, Damm DD, Allen CM, Chi AC. Patologia oral e maxilofacial. Elsevier, Rio de Janeiro, Brazil, 2016.

Oliveira SMM, Lorscheider J, Nogueira MA. Avaliação da ação in vitro de gel dentifrício contendo óleos essenciais sobre bactérias cariogênicas. Lat Am J Pharm, 2008; 27:266-9.

Pader M. Dental products. In: Williams SD, Schmitt WH (ed.). Chemistry and technology of the cosmetics and toiletries industry. Blackie Academic and Professional, Glasgow, Scotland, pp 210-57, 1992.

Pardeshi MD, Tapar KK. Formulation and evaluation of aloevera gel with active salt and alum: as a new dentifrice. Int J Res Econ Social, 2016; 6:297-310

Pérez-Ibarbia L, Majdanski T, Schubert S, Windhab N, Schubert US. Safety and regulatory review of dyes commonly used as excipients in pharmaceutical and nutraceutical applications. Eur J Pharm Sci, 2016; 93:264-73.

Rodero AB, Rodero LS, Azoubel R. Toxicity of sucralose in humans: a review. Int J Morphol, 2009; 27:239-44.

Rowe RC, Sheskey PJ, Owen SC. 2012. Handbook of pharmaceutical excipients. Pharmaceutical Press, London, UK.

Ruiz-Ojeda FJ, Plaza-Díaz J, Sáez-Lara MJ, Gil A. Effects of sweeteners on the gut microbiota: a review of experimental studies and clinical trials. Adv Nutr, 2019; 10(1):S31-48.

Russo D, Merolla F, Varricchio S, Salzano G, Zarrilli G, Mascolo M, Strazzullo V, Di Crescenzo RM, Celetti A, Ilardi G. Epigenetics of oral and oropharyngeal cancers. Biomed Rep, 2018; 9:275-83.

Sälzer S, Rosema NA, Martin EC, Slot DE, Timmer CJ, Dorfer CE, van der Weijden GA. The effectiveness of dentifrices without and with sodium lauryl sulfate on plaque, gingivitis and gingival abrasion-a randomized clinical trial. Clin Oral Investig, 2016; 20:443-50.

Saunders DP, Epstein JB, Elad S, Allemano J, Bossi P, van der Wetering MD, Rao NG, Potting C, Cheng KK, Freidan A, Brennan MT, Bowen J, Dennis K, Lalla RV. Systematic review of antimicrobials, mucosal coating agents, anesthetics, and analgesics for the management of oral mucositis in cancer patients. Support Care Cancer, 2013; 21:3191-207.

Savary G, Gilbert L, Grisel M, Picard C. Instrumental and sensory methodologies to characterize the residual film of topical products applied to skin. Skin Res Technol, 2019; 25(4):415-23; doi:10.1111/ srt.12667. (Accessed 01 April 2019). 
Sciubba JJ, Goldenberg D. Oral complications of radiotherapy. Lancet Oncol, 2006; 7:175-83.

Sinko PJ, Singh Y. Martin's physical pharmacy and pharmaceutical sciences: physical chemical and biopharmaceutical principles in the pharmaceutical sciences. Lippincott Williams and Wilkins, Philadelphia, PA, 2011.

Stovell AG, Newton BM, Lynch RJ. Important considerations in the development of toothpaste formulations for children. Int Dent J, 2013 63(2):57-63.

Strojan P, Hutchesonb KA, Eisbruchc A, Beitlerd JJ, Langendijke JA, Leef AWM, Corryg J, Mendenhallh WM, Smeei R, Rinaldoj A, Ferlitok A. Treatment of late sequelae after radiotherapy for head and neck cancer. Cancer Treat Rev, 2017; 59:79-92.

Swarbrick J, Boylan JC. Encyclopedia of pharmaceutical technology, vol. 2. Marcel Dekker, New York, NY, 2002.

Teles RP, Teles FRF. Antimicrobial agents used in the control of periodontal biofilms: effective adjuncts to mechanical plaque control? Braz Oral Res, 2009; 23(Suppl 1):39-48.

Triratana T, Kraivaphan P, Amornchat C, Mateo LR, Morrison BM Jr, Dibart S, Zhang YP. Comparing three toothpastes in controlling plaque and gingivitis: a 6-month clinical study. Am J Dent, 2015; 28:68-74.

Tuncer Budanur D, Yas MC, Sepet E. Potential hazards due to food additives in oral hygiene products. J Istanb Univ Fac Dent, 2016; $50: 61-9$.
Vissink A, Mitchell JB, Baum BJ, Limesand KH, Jensen SB, Fox PC, Elting LS, Langendijk JA, Coppes RP, Reyland ME. Clinical management of salivary gland hypofunction and xerostomia in head-andneck cancer patients: successes and barriers. Int J Radiat Oncol Biol Phys, 2010; 78:983-91.

Wulf NR, Matuszewski KA. Sulfonamide cross-reactivity: is there evidence to support broad cross-allergenicity? Am J Health-Syst Pharm, 2013; 70:1483-94.

Zado LN, Pilatti GL. Dentin hypersensitivity: recent advances and treatments - literature review. Braz J Periodontol, 2016; 26:28-33.

\section{How to cite this article:}

Ribeiro ACL, da Silva MG, Tavares HDS, Solano AGR, Gomes AJPS. Study of a tooth gel formulation for hygiene and oral sequelae management in irradiated patients. J Appl Pharm Sci, 2020; 10(06):116-122. 